\title{
SIMPLIFIED OPERATION MANUAL PA-720 \\ PARTICLE COUNTER
}

Victor F. Draper

\section{MASTER}

September 8, 1980

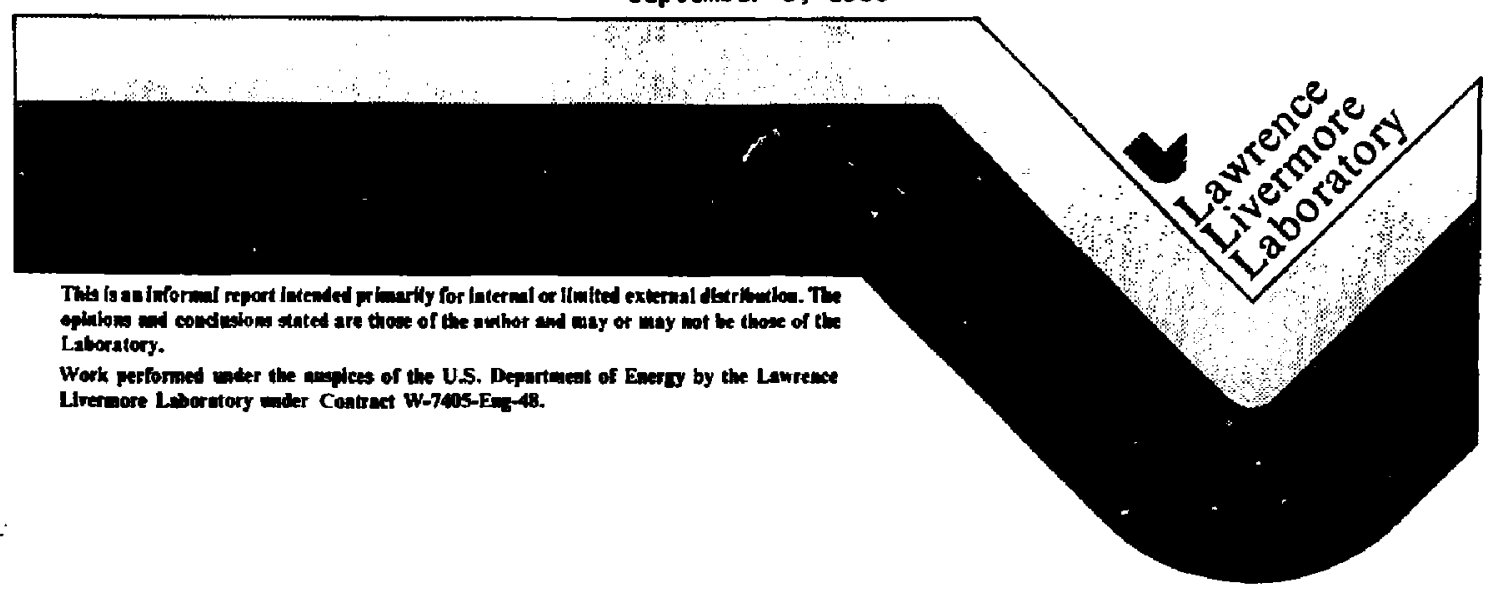




$\begin{array}{lr}\text { ABSTRACT } & 1 \\ \text { INTRODUCTION } & 2 \\ \text { GENERAL SYSTEM DESCRIPTION } & 2 \\ \text { SPEC IFICATIONS } & 5 \\ \text { OPERAT ING PROCEDURE } & 6 \\ \quad \text { ANALYZER CONTROLS } & 7 \\ \text { TELEF :NTER CONTROLS } & 9 \\ \text { PLOT FORMATS } & 14 \\ \text { START-UP PRCCEDURE } & 15 \\ \text { PCB SWITCH LOCATION AND FUNCTION } & 16 \\ \text { TEXT ENTRY } & 17 \\ \text { SPECIAL COMMANDS AND MODES } & 20 \\ \text { SYSTEM OPERATION } & 20 \\ \text { OVERSIZED PARTICLES } & 23 \\ \text { DATA ENTRY ACCESS COMMANDS } & 25 \\ \text { TECHNIQIIE AND APPLICATION SUGGESTIONS } & 26 \\ \text { APPENDIX A: } & \\ 4 \text { SAMPLE RUNS AND ANALYSIS } & 31 \\ \text { APPENDIX B: } & 47 \\ \text { CALIBRATION DATA SHEET } & \end{array}$

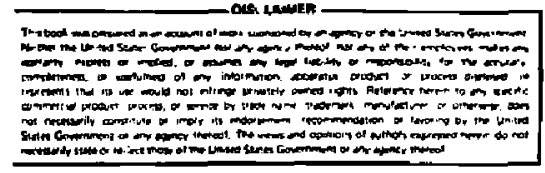


ABSTRACT

The model PA-720 Autonatic Particle Size Analyzer is a simple, relatively high speed device designed to provide accurate size distributions in hoth tabular and graphic forms. This model has two dynamic ranges; 50-2500 microns and 200-1600 microns.

This is an abbreviated version of the manufacturer's operating manua 1. It provides all the necessary information for the novice and experienced user. For more detafled explanations and servicing procedures one should reference the full manual. 
INTRODUCTION

PURPOSE OF THE INSTRUMENT

An advanced Particle Size Analys is System was developed to provide greater insight into the size and distribution of particles within a sample.

The Model PA-720 Automatic Particle Size Analyzer is designed to provide high-ejed, precise particle size distribution analysis on a wide variety of naterials, and to present the particle size distribution data in both tabular and $X-Y$ graphic forms.

GENERAL SYSTEM DESCRIPTION

The HIAC Model PA-720 Automatic Particle Size Analysis System is designed to analyze particulate systems. The microprocessor based Central Processing Unit (CPU) provides ease of operation, calculating capabilities, and printed and plotted output formats. The 24 data thresholds may be programed to cover two available analysis ranges having size ratios of $45: 1$ and $8: 1$ expressed in terms of equivalent spherical dianeter.

The two programmable threshold groups provide for calibration of the system to any two sensor and anaysis range combinations. These groups are operator selectable, thus aliowing a change in analysis range without reprograming or substituting circuit boards. 
Operator communication with the system is accomplished through a keyboard which is part of the peripheral teleprinter. Sample and lest identification, as well as analysis parameters are entered through the keyboard. This information may be modified by the operator at the beginning of any test sequence.

l'p to five replicates may be included in the analysis. Results are ca?culated using the average of the replicate raw data. The system also jrovides for the ident ification and subtraction of "background" distributions.

The system provides a two part output which appears as a printout and $X-Y$ plots. Both population and volume data and analyses are presented. The printout appears on two $11 \times 81 / 2$ sheets. The sheets are connected by perforations and the sample identification cocie is reproduced on the second sheet to supply identification if the two sheets happen to become sep arated.

The printout contains four sections:
a) Title Block.
b) Raw Data Table.
c) Analysis Table.
d) Summary Table.

The Title Block contains sample, equipment, operator, and date code identification, is well as test and analysis parameters.

The Raw Data Table presents the actual particle count determined for each of the 24 data channels for each replicais in the total test run.

The Analys is Table is a tabular presentation, for all 23 class intervals, of the mean size class diameter, the average, background, and corrected particle counts, as well as the percent differentiai, percent smaller than, and percent larger than a given class size for both 
population and volume. In addition, the standard deviation of the differential population is determined for each size class to give insight into the repeatability of the replicates. Also, the count of particles larger than the highest data channel is given to support the validity of the volume data.

The Summary Table presents, for both population and volume, the mean and median particle diameters as well as the diameters at two other percentage points selected by the operator. The two diameter ratios are also determined to indicate symmetry and slope of the distribution.

The Plotter provides an output consist ing of a set of six curves. These curves are plotteo on direct reading plot paper. The operator selects the curve or curves which are best suited to his purpose. Multiple copies of the same curve may be obtained. The set of curves represent the following analyses:

a) Percentage of the total number of particles greater than a stated size.

b) Percentage of the tocal number of particles smaller than a stated size.

c) Percentage of the total volume of particles greater than a stated size.

d) Percentage of the total volume of particles smaller than a stated size.

e) Percentage of the total number of particles equal to a stated size. (Population Differential.)

f) Percentage of the total volume of particles equal to a stated size. (Volume Differential.)

The particle sensor operates using the HIAC principle of light blockage. 


\section{SPECIFICATIONS}

GENERAL

This section contains specifications for the HIAC Model PA-720 Automatic Particle Size Analysis System which includes the Analyzer. Teleprinter, and Plotter.

MODEL PA-720 ANALYZER

Analysis Range Ratios

$45: 1,8: 1$

(Operator Selectable)

Number of Data Channels 24

Size Thresholds (Normalized)

$1,1.18,1.39,1.64,1.94,2.29$,

$2.70,3.19,3.76,4.44,5.23$,

$6.18,7.29,8.60,10.1,12.0$,

$14.1,16.7,19.7,23.2,27.4$, $32.3,38.1,45.0$

Number of Threshold Groups

Two

Background Correction

Automatic on Operator Request

Multiple Replicate Analysis

up to Five

Selectable Sample Sizes

1K, 10K, 100K, 1M Particles per

sample and indeterminant. 


\section{OPERATING PROCEDURE}

PHYSICAL DESCRIPTION

The PA-720 Automatic Particle Size Analysis System is packaged in four enclosures. The primary unit is the Analyzer itself. Peripheral to the Analyzer is a Teleprinter and Plotter. The Sample Delivery System completes the configuration.

The PA-720 sorts part icle data into 23 class intervals of constant percentage width. The 24 voltage dividers required to establish the size thresholds are mounted on a single plug-in printed circuit board (PCB 6). In multi-range systems, PCB 6 contains two groups of dividers which are operator selectable.

Except for display circuitry, sample size logic, and sample sequence timers which are on a printed circuit board attached to the front pane?, all of the electronic circuits are contained on PCB's winich plug into a card cage accessible through the rear access panet. 


\section{ANALYZER CONTROLS}

START - (Control Group)

At appropriate points in the operating sequence this momentary push button switch, when depressed, will initiate the sampling operation.

STOP - (Control Group)

At appropriate points in the operating sequence this momentary push buttan switch, when depressed, will terminate the sampling operation, terminate the analysis and summary print out, abort a particular plotting operation, or terminate all plotting opportunities and reset the operating sequence.

PLOT/CALC - (Control Group)

At appropriate points in the operating sequence this momentary push button switch, when depressed, will initiate data analysis or will initiate the plotting of analys is requests.

POPULATION (POP) - (Plot Group)

This interlocking push button switch, when depreszed, will select the population data format (as opposed to volume format).

VOLIME (VOL) - (Plot Group)

This interlocking push button switch, when depressed, will select the volume data format (as opposed to population format).

PERCENT GREATER $(\%>)$ - (Plot Group)

This interlocking push button switch, when depressed, will select the data format which displays the percentage of particles greater than a given size or volume. 
PERCENT EQUAL (DELTA) - (Plot Group)

This interlocking push button switch, when depressed, wi7l select the data format which displays the percentage of particles equal to a given size or volume.

PERCENT LESS $(\%<)$ - (Plot Group)

This inter locking push button switch, when depressed, will select the data format which displays the percentage of particles smaller than a given sjze or volume.

DELTA FULL SCALE SELECT GROUP

When the instrument is set to present a "delta" plot, the DELTA FULL SCALE SELECT GROUP determines the full scale range of the $Y$-Axis. Expansion of the $Y$-Axis data allows higher resolution delta plots enabling the operator to more easily determine the mode point of particle systems exhibiting flat distributions. The switch selected determines the full scale reading of the plot paper.

IK, 10K, 100K, 1M - (Size Group)

These interlocking push button switches, when depressej will select the number of particles which constitute a complete sample. Four sample sizes are selectable $-1,000,10,000,100,000$ and 1,000,000 particles.

MANUAL (MAN) - (Size Group)

This interlocking push button switch, when depressed, disables the sample size switches discussed in the previous paragraph. The sample operation may be stcpped by using the STOP switch or by the appropriate control signal from the Volume Sample Delivery System or the Ory Sample Delivery System. 
TOTAL COUNT OISPLAY

Indicates the total number of particles that have been processed during a sample operation.

OVERSIZED DISPLAY

Indicates the total number of particies, whose sizes are greater than the largest size threshold, on which the system has attempted processing.

READY INDICATOR

This indicator, when illuminated, shows that the system is reary to accept a new command. The indicator is "OFF" during sampling, analys is, and data plotting operations.

SENSOR INDICATOR

THIS INDICATOR, WHEN "OFF", CONFIRMS THE MORMAL OPERATION OF THE SENSOR. THE INDICATOR WILL BE ILLUMINATED UNDER THE FOLLOWING CONDITIONS:

a) SYSTEM IS NOT PERFORMING A SAMPL ING OPERATION.

b) FLASHING, DURING THE SAMPLING OPERATION, INDICATES AN OVERCONCENTRATION CONDITION IN THE SAMPLE.

C) STEADY ILLUMINATION, OURING THE SAMPLING OPSRATION. INDICATES A BLOCKED SENSOR (I.E., LIGHT NOT BEING TRANSMITTED THROUGH THE SENSOR AND POSSIBLE BLOCKAGE).

\section{TELEPRINTER CONTROLS}

\section{LOCAL MODE SELECT}

This push button suitch, when depressed, sets the Teleprinter to the local mode. In this mode, operations on the keyboard will be printed. but will not he transmitted. 
DATA MODE INDICATOR

This indicator, khen illuminated, shows that the Telepririter is in the data mode. This is the normal operating mode for this system.

TERMINAL READY

This push button switch, when depressed, sets the Teleprinter to the data mode. In this mode data may be transmitted from and received by the Teleprinter.

ALARM INDICATOR

This indicator, when illuminated, indicates that an alarm condition exists. Teleprinter operation will stop until the condition is cleared. The alarm condition that may be encountered is the "out of paper" condition.

PRINTER TEST

This push button switch, when depressed, enables the printer test function. Operation of this function places the Teleprinter in the local mode. Recovery to the data mode is made by depressing the TERMINAL READY switch.

PARITY

This switch must be in the up position to set the parity status to oN. DUPLEX

This switch must be in the down position to set the duplex status to FULL DUPLEX MODE. 
CPS (CHARACTERS PER SECOND)

This switch must be in the up position to set the rate to 300 CPS.

CAPS LOCK

This switch must be in the down position to select the all upper case (capita1) status.

PRINTOUT FORMAT

Tive size analysis printout appears on two $11 \times 8-1 / 2$ inch sheets which are connected by perforations.

The printout contains four sections:

a) Title Block.

b) Raw Data Table.

c) Analysis Table.

d) Summary Table.

The Title Block contains sample, equipment, operator, and date code identification, as well as test and analysis parameters. All of this information has been entered by the operator prior to the beginning of the test sequence. The Title Block is a reproduction of this information so that it is uncluttered by editing or corrections.

The Raw Data Table presents the actual particle count determined for each of the 24 data channels. This data is presented for each replicate in the test run. Each set of data is numbered in sequence. The data for each replicate is presented in two rows, thus the first column contains the data for channel 1 followed by the data for channel 13. The remaining columns present data in the same format.

The Analysis Table is a presentation of the distribution results over the 23 class intervals. The first column (i) is the interval number. 
The Class Interval Mean Dianeter is presented in column $d(i)$. The next ihree columns present particle count data. The first gives the average particle count as determined from the raw data. The second gives the background count which has been entered into memory following a previous analysis. The third gives the "corrected particle count", that is, the average minus the background. The remaining seven columns are divided into two groups - population and volume. Each group presents the percent differential, percent finer than, and percent larger than a given class size as a function of class interval. In addition, the standard deviation of the differential population is detarmined for each class interval to give insight into the repeatability of the replicates.

The sample identification code is presented to assist in identification in case the two sheets become separated. The 24th class interval presents the count of particles larger than the highest data channel. This is given to support the validicy of the analys is particuiarly the volume anaiysis.

The Summary Table presents six distribution parameters for both population and volume. The first is the particle diameter at the MEAN of the distribution. The mean is one of three parameters which are frequently used to describe the central tendency of a distribution. The mean has been characterized as the center of gravity or the balancing point of the differential distribution. It is defined as the algebraic sum over the 23 ciass intervals of the product of the particle count and its associated diameter (or volume) divided by the total number of particles. The mean is greatly influenced by extreme values.

The second parameter used to describe the central tendency of a distribution is the MEOIAN and is shown as $f(50)$. The median is the point at which half of the particles are larger and half are smaller.

The third parameter used to describe the central tendency of a distribution is the MODE. This is simply the point at which the most 
particles appear. It is the peak of the differential distribution. This parameter is not presented in the analysis, but rather is left to the operator to determine from the differential distributions. Although its definition is quite clear, in practice many distributions are bi-model or even tri-model, having two or three peaks of different significance.

In addition to the median, the diameters associated with two additional percentage points on the percent finer than distribution curve are given. The points, $Y 1$ and $Y 2$, have previous $1 y$ been determined by the operator and appear in the TitTe Block as $p(Y 1)$ and $p(Y 2)$.

Finally, two diameter ratios are given insight into the dispersion, symmetry, and slope of the distribution. The lower the value for each of these ratios, the narrower the distribution. If both values are 1.0 the material is mono-sized over the analys is range. If $p(Y 1)$ is defined as $16 \%$ and $p(Y 2)$ is defined as $84 \%$, and if the two ratios are the same value, the distribution can be considered log-normal.

Below these summiary figures appears the results of the acceptance testing. This feature will be discussed in a following paragraph.

The PA-720 is capable of analysis of the average of up to five replicates. When only one replicate is collected and analyzed, the standard deviation calculation cannot be performed. This situation is verified by the dashes in the standard deviation (SD) column of the printout.

To assist in obtaining a valiu and reliable analysis of the primary particle system, the PA-720 has a BACKGROUND subtraction capability. Background data is collected by analyzing the carrier gas in the same manner as any other sample. Fnllowing the analysis, the average particle count for each class interval may be saved in the "background" memory for use in subsequent analyses. Background subtraction may be turned on or off by the operator. The off condition is indicated by the dashes in the 
background (BKG) column of the printout. The on condition results in the background data appearing in the BKG column and the subtraction of this data from the average (AVG) data yielding the corrected particle count (CPC).

ACCEPTANCE TESTING is the ability to determine if a variable result falts within a given tolerance of an expected value. The PA-720 is capable of performing this analysis on the dismeters associated with $p(Y 1), p(50$, and $p(Y 2)$ of the volume summary. In order to implement this test the operator must enter the diameters expected at the $Y 1,50$, and $Y 2$ percentage points on the volume percent finer than curve. He must also enter the allowable tolerance percentage for each diameter.

Following the distribution analysis the volume summary results will be tested against the expected values. Each of the three diameters is tested independently. If the test result is positive no indication is printed. However, if the actual diameter falls outside of the acceptable limits an error flag will be printed. This flag appears as a series of astericks $(\star \star \star \star \star \star)$ under the out of tolerance diameter.

\section{PLOT FORMATS}

The graphicat prerontations of the PA-720 are continuous curve plots representing a reasona - interpolation of the fjelds between data points.

The curves are referenced to different points depending on the data being represented. The differential curves are plotted against the mean diameter of the class interval. The percentage greater than curves are plotted against the lower $l$ imit of the class interval, while the percentage smaller than curves are plotted against the upper 1 imit of the class interval. These offsets are controlled automatically by the PA-720.

Many distributions have broad differential curves. To increase the resolution of these plots, the PA-720 provides a scale expansion capability, that is, the full scale value of the grid may be set to 25\%, or $100 \%$ by use of the DELTA FULL SCALE select switches. 


\section{STA.RT UP PROCEDURE}

While there are many combinations of switch settings possible, the following procedure is recommended while the operator becomes familiar with the eouipment.
a) Analyzer, Teleprinter, and Sampler POWER off.
b) POP depressed.
c) $\%>$ depressed.
d) MAN depressed.
e) DELTA 100\% depressed.
f) PARITY up.
g) DUPLEX down.
h) CPS up.
i) Sampler AUTO/MAN in AUTO.
j) Vibratory feeder control fully CCW.
k) Paper in Teleprinter and on Plotter. 
PCB SWITCH LOCATION AND FUNCTION

Location Switch Name Position Reference Section

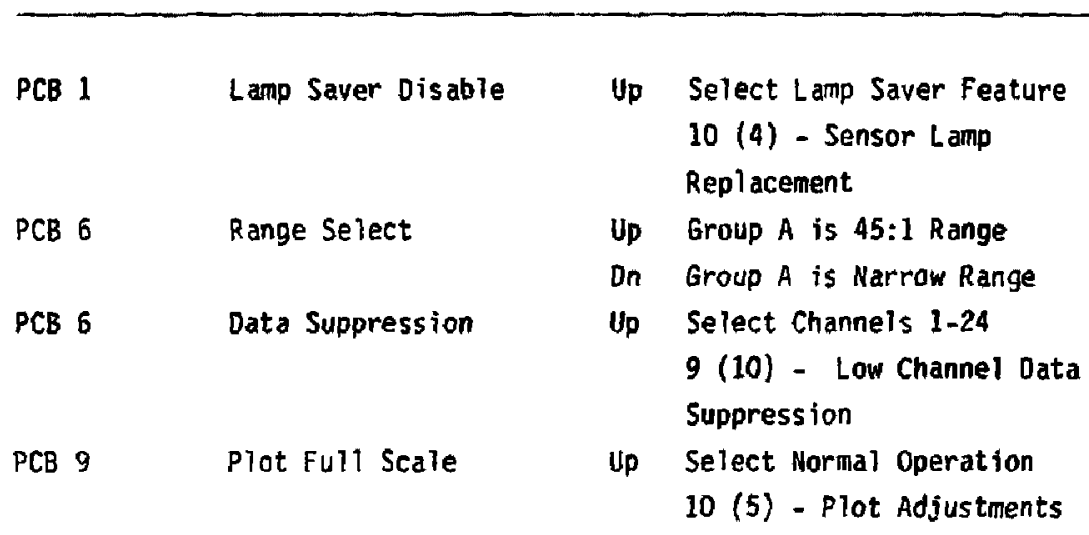


Turn on the Teleprinter POWER switch. After power is turned on, adjust the paper using the PLATEN KNOB so that the top edge of a form (perforation) is at the rear tearing edge of the PAPER SEPARATOR.

Turn on the Analyzer POWER switch. Verify that the Teleprinter's DATA indicator is on. If the TERM ROY indicator is on, correct the condition. The Teleprinter will request text entry by printing SAMPLE: $>$ at the left margin.

Turn on power to the Sample Delivery System.

Allow the system to stabilize for approximately 10 minutes before running a replicate. This warm-up period allows the Piotter to stabilize. Text entry may be performed during this period.

\section{TEXT ENTRY}

Text Entry provides for the input, correction, and modification of identification and analys is parameters.

There are a number of parameters which must be ident ified. They are listed below, with their identification.

a) SAMPLE - Identification of the sample under sturly.

b) SENSOR - Identification of equipment used in the analys is.

c) OPERATOR - Identification of the equipinent operator.

d) DATE - Ident ification of the date.

e) RANGE - Dynamic range of test, ie. $45: 1$, etc.

f) THRESH - Threshold group select.

g) DIA(1) - Diameter represented by channel 1 of the selected threshold group.

h) $p(Y I)$ - Percentages at which the particle diameters will be $p(Y 2)$ - determined from the percent smaller than data.

i) EXPdY1 - The diameter expected to result from the EXPd50 - analysis at the percentages defined above, EXPdY2 - as well as at $50 \%$. 
j) TOLdYl - The allowable tolerance within which the TOL $\$ 50$ - analysis result must fall in relation to TOLdY2 - the expected diameter in order to be considered acceptable.

k) BKG - Request to change status of background subtraction.

1) VOL - Sample volume for solids cetermination.

m) DIL - Dilution Ratio of sample for solids determination.

n) SLOPE - Slope constant (K) from sensor calibation curve.

o) INTRCP - Intercept figure (A) from sensor calibratiori curve.

p) NOISE - Noise figure from sensor calibration curve.

If the opcrator enters numerical data beyond the field limit for the parameter in ouestion, the data will be rounded upon echo, but the original entry will be used in analysis calculations. Thus, a DIA(1) entry of 50.453 will be echoed as 50.5 , but the original entry will be used in the calculations.

Each parameter is prompted by one of the "echo back" words followed by the current value of the parameter (usualiy null at power turn on, ie. undefjned) and the prompting character "s". The operator should then type in the desired value of the parameter followed by a carriage return. The parameter value is entered into memory and the prompting sequence requests the next entry.

At power turn on the system will automatically inftiate the prompting dialog for the 15 mandatory operation parameters. All entries must be made. If the operator makes no entry the word INVAL IO is printed and the prompt is repeated.

All numerical data entries are tested for legality. The oid data will be retained until the operator enters legal data. For all prompts, characters entered beyond the 20 character limit are simply ignored.

Errors in data entry can be corrected as they are made, that is, before the carriage return is struck, hy means of the DELETE key. A 
backward carat $(<)$ is printed in response to the DELETE, and the last character is internally deleted. Repeated use of the DELETE key will delete successive characters moving from right to left through the data entry.

At any point in a data entry between the prompt $(\cdot \cdot)$ and the carriage return, striking the ESC (escape) key will cause the prompt to be repeated and any previous key strokes are lost.

Once the mandatory parameters are enteren, a prompt is printed and the READY indicator is turned on.

With thr prompt at the left margin, :he coerator may type any of the command keywords. These keywords are used to call up a single paraneter without having to go through the complete prompt sequence. The system will examine only the underlined characters of the keyword entry, thus $B$, BACKGROUND, and BKG will be interpreted is a "background" command.

If the operator entry does not match any of the underlined portions of a keyword, the system will print "??" and repeat the prompt character.

Whei the entry is completed, the prompt character will again be typed at the left margin, allowing the operator to enter another keyword command if desired, or to start the firsi replicate.

The command LIMITS, ACCEPTANCE, VOLUPE, and CALIBRATE are multi-parameter commands which initiate the sequence of echo back words. PROMPT causes the entire power-on prompt ing sequence to be repeated, while echoing the current parameter values.

The ident ification and analys is parameters need nnly be entered after power turn on as they will be retained until power is turned off. However, they may be changed at anyt ime that a prompt character appears at the left margin. 
SPECIAL COMMANOS AND MODES

The VERIFY command causes the system to print out the current value of each parameter.

The STORE command is given after a group of replicates have been analyzed.

The BACKGROUND Command allows the operator to control the background subtraction operation.

The VOLUME command allows the operator to enter the sample volume in milliliters and a dilution factor.

The CALIBRATE commard is used to invoke the Calibrate Program. This program is independent from all other functions of the system and is used to determine the threshold voltage values for calibration of PCB 6 .

\section{SYSTEM OPERATION}

After the power-on prompting, and at any time when the prompt character ( $>$ ) appears at the left margin, the operator may press the START button to initiate the counting of the first replicate.

While the REAOY lamp is off, no front pasel or keyboard syitches are functiona1, excepting the STOP switch whose multi-functions will be discussed in this section. However, there is one exception to this rule - during the counting process the START switch may be used to "restart" a replicate. The counters will be cleared to zero and the data collection process will be reinitiated. This feature is incorporated to allow the operator to make system adjustments without affecting the data callection process. 
The Sample Delivery System will begin operation and normal operat ing voltage will he applied to the Sensor's Lamp. The Front Panel Display will show that counting has started.

The Front Panel SENSOR Lamp should go out a couple of seconds before counting begins. If it stays on, or cones on and glows steadily during a run, a blocked sensor is indicated. If it flashes at a steady rate, the sample is overconcentrated, causing more than one particle to be in the sensing zone at one time. In either case, the run should be aborted by pressing the STOP switch, and appropriate action should be taken to correct the condition.

Counting may be terminated by one of the following methods. Automatically upon reaching the preset 1 imit selected by one of the SIZE GROUP switches, or manuatly by pressing the STOP switch. In the first case, the contents of the counters are transferred to the data memory at the end of the run. For a manually terminated run, however, this transfer takes place only when the PLIT/CALC switch is pressed following the pressing of the STOP switch, and then only if no automatically terminated runs have been taken in the current group of replicates. If both of these conditions are not satisfied, the counts from a manually terminated run are discarder. These conditions will allow the analys is of only one manualiy terminated replicate, but will allow the analysis of up to five automatically terminated replicates while, in adcition, allowing the operator to manually abort obviously defective replicates during processing.

At the completion of the first autematically terminated replicate, the Title Block is printed and the Raw Data Table is constructed, including the data from the first replicate, and the READY lamp is turned back on.

The operator may begin another replicate by pressing the START switch as before. Up to five replicates may be collected in this manner. 
Alternatively, the operator may press the PLOT/CALC switch to initiate the data analysis calculations and printout. After the raw data for the fifth automatically terminated replicate in a group has been printed, analysis calculation proceeds automatically without waiting for the operator to press the PLOT/CALC switch. The READY lamp is turned off during the calculation process and only the STOP switch is functional.

In the manual mode, that is, when the SIZE GROUP is set to MANUAL, the analysis calculations for a manualiy terminated run are initiated by pressing the PLOT/CALC switch. It is at this time that the Title Block and Raw Data Table, including the Jata from the manually terminated "un, are printed. The analys is calculations are then performed without further action by the operator.

nnce the analysis calculations have begun, the Analysis Table and Sumary Table are automatically printed. If desired, the operator may skip all or part of this portion of the printout by pressing the STOP switch or the ESC (escape) switch on the keyboard.

If the plotter is part of the system configuration, the READY Iamp will turn on following the printing of the Summary Table, at which time a plot may be generated by pressing the PLOT/CALC switch.

Five push button switches comprise the $X-Y$ PLOT select group. The type and form of the desired data plot are selected by depressing the appropriate switches.

Three types of plots are available:

a) Percentage greater than a stated size $(x>)$.

b) Percentage smalier than a stated size $(\%<)$.

c) Percentage equal to a stated size - differential curve (DELTA).

All of these types are availatle in two forms:

a) As a function of the total number of particles (POP).

b) As a function of the total volume of particles (VOL). 
When the DELTA Plot is selected, the DELTA FULL SCALE switch group determines the full scale range of the $Y$-Axis. Expansion of the $Y$-Axis data allows higher resolution delta plots enabling the operator to more easily determine the mode point of particle systems exhibiting flat distributions. The switch selected deternines the full scale reading of the plot paper.

Additional plots may be ae lerated on demand by pressing the PLOT/CALC switch when the READY lamp is on. The plot format is determined oy depressing the appropriate selection switches.

If the STOP switch is pressed during a plot operation, the current plot operation is aborted, but additional plots may be generated by pressing the PLOT/CALC switch.

If the STOP switch is pressed before or after a plot operation, all plot functions are terminated and the printer will respond with a prampt character. This indicates that a conmand keyword may be entered or that the next group of repilicates may be begun. No further plots of old data aro possible.

\section{OVERSIZED PARTICLES}

The oversized display counts the nimbar of particles larger than the highest size threshald (f24). If the display indicated 50 aversized particles in a 10,000 particle sample and the data presentation was in the POPULATION mode, the error would be 50 out of 10,000 or $0.5 \%$ which would be negligible.

If, however, the data plot was in terms of percent of total volume, the error would be much greater. Assume that particles in the 1-45 im range were being analyzed and that the DELTA plot was symmetrical with the mode occurring at $8 \mu \mathrm{m}$. The product of the number of particles and the weighing factor would be

$$
10,00 \times 387=3.87 \times 10^{6}
$$


and represents the total sample volume. If we now assume that the 50 oversized particles had an average diameter of $45.1 \mu \mathrm{m}$, the average weighing factor is approximately 69,000 and the product becomes $50 \times 69,000=3.45 \times 10^{6}$

Note that the 50 oversized particles are not included in the analys is of the 10,000 particles. Therefore, the actual sample volume is $13.87+$ 3.45) $\times 10^{6}$ and thus the original "total sample volume" is in error by almost $50 \%$.

From this oversimplified example it is clear that when accurate volume distribution results are desired, $.05 \%$ oversized particles (ie., 5 in $\mathrm{a} 10,000$ sample) are cause for concern. 


\section{DATA ENTRY ACCESS COMMANDS}

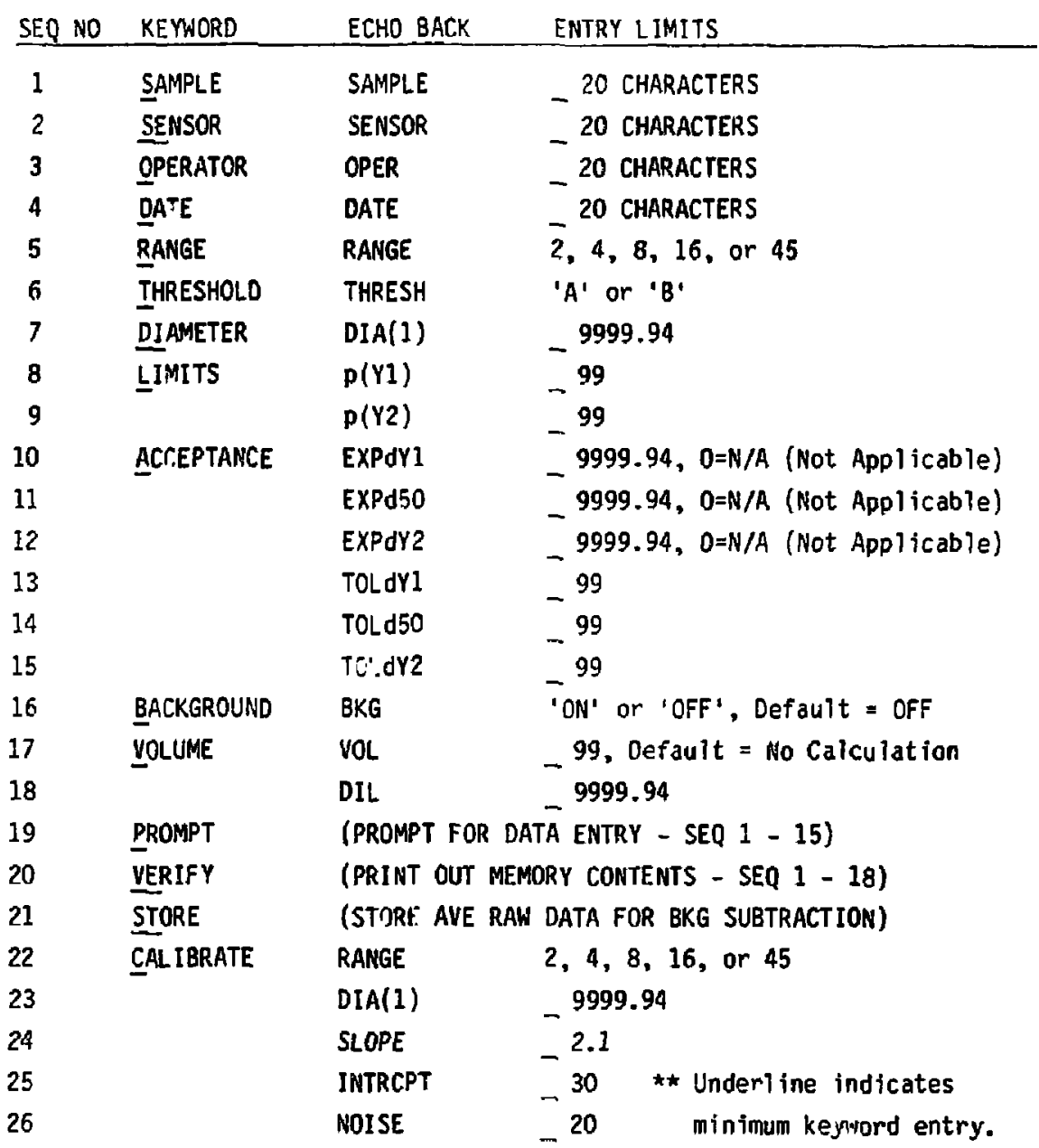




\section{TECHNIQUE AND APPLICATION SUGGESTIONS}

GENERAL

This section contains a discussion of some basic suggestions to cansider when operating the PA-720. Many problems can be traced direct.ly to unfamiliarity with general contamination control and/or particle technology principles.

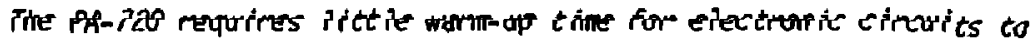
stabilize. The instrument will be ready for operation within ten minutes after turning on power.

\section{SAMPLE CONTAINERS}

Clean sample containers must be used at all times to avoid contamination of the sample.

FLOW RATE

While technical advances in sensor design have made the sensors essentially insensitive to flow rate variations, it is recommendey that analusis be performed at the rates recomended; i.e.s 100 count

\section{PARTICLE SIZE DEFINITION}

Much confusion exists in the field of fine particle technology regarding calfbration. This is a result of the many different definitions of particle size in use. A11 of the definitions are correct in their own right, but do produce different data because they are all based on different particle parameters. Factory Calioration indicates that the factory calibration. uses spherical particles. Calibration Verification and Plot Adjustments and Interpretation discuss methods of compensation for parameter differences. 
SENSOR MAINTENANCE AND CLEANING

It is important that the Sensor be kept as clean as possible to assure maximum performance. Partial or complete Sensor blockage will occur if particles larger than the sensing zone are allowe-- ia enter the sensor. Remove the sensor and insert a cleaning probe directly into the outlet side of the sensor to push the particles out through the inlet side. Compressed air, directed from the outlet side, may also be used to dis lodge blockage.

\section{PLOT ADJUSTMENTS AND INTERPRETATION}

The set of six curves representing the particle distribution are referenced to different points. The differential curves (percentage of population or volume equal to a stated size) are plotted against the mean diameter of the class interval. When plotting percentage greater than a stated size, the data points are plottej against the lower limit of the class interval. When plotting percentage smaller than a stated size, the data points are plotted against the upper 1 imit of the class interval. These off-sets are controlled automatically by the PA-720.

The plots associated with narrow range analyses are always plotted on the appropriate regions of the ir respective plot papers and actual particle size is determined by simpie multiplication. However, plots generated by the 45:1 analysis are direct reading. Therefore, the plot must be appropriately positioned on the plot paper, to correspond to the sensor being used. An adjustable $X$-AXIS OFFSET control is provided on PCB 6 (Threshold Level Adjust) for this purpose.

Since particle diameter is displayed on a logarithmic scale, applying an offset voltage to the $X$-Axis of the plotter will simply shift the whole size distribution curve without changing its shape. 
LOW CHANNEL DATA SUPPRESSION

The analysis of some particle systems may indicate the presence of very small particles which clearly are not part of the main distribution. These particles may be debris resulting from the breakdown of the main system components or ext:aneous particles which are not part of the main system, but have found the ir way into the sample.

Curve " $A$ " below indicates how an analysis of this type of sample may appear on a plot of percent greater than a given size. The effect of the small particles is to suppress or reduce the $100 \%$ level of the main system.

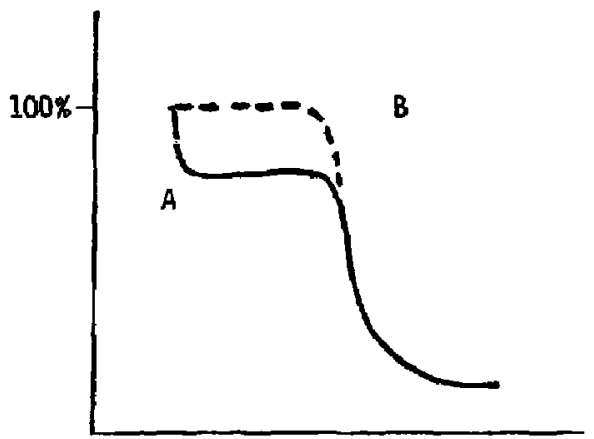

The data in the first four channels may be suppressed (i.e. - no counts will be recorded in the first four channels) simply by moving the DATA SUPPRESSION switch on PCB 6 to the down position. Curve "B" illustrates how the data output may appear after the data is suppressed resulting in a plot which is direct reading for the main particle system. 


\section{SAMPLE FEEDER}

The vibratory feeder provides two sets of knife edge adjustments to insure single particle travel into the sensor. A general rule of thumb for the last knife edge spacing is to adjust the opening to a minimum of three (3) times the maximum particle dimension. That is, for a replicate distribution of 100 to 420 microns this opening should be set at approximately 1260 microns. The first knife edge set, while not as crucial, should have an opening to insure a uniform flow of particles to the 2 nd l.nife edge set.

\section{SAMPLE SELECTION}

The advantage of this device over other partiale count ing systems which rely on a solution to disperse the particles is its insensitivitv to size or bulk density.

As a consequence of this however, proper samplin. techniques must be adhered to. It is not sufficient to scoop or tap a small replicate from the sample. Doing so will result in a distribution that is biased due to the sampling technique and will not be a true representation.

A sample splitter is provided and should be used whenever a distribution is required and the sample must be retained. Operation of the splitter is simple. Depending upon sample size, you may wish to split the sample in half, or its half in half (1/4) or its quarter in half $(1 / 8)$, etc. until reaching a fraction you believe will give you a significant count to insure a true distribution.

Additionaliy, due to the nature of the vibratory feeder mechanism, it is essentialiy that once a replicate has been started it be countinued until all particles have been sensed. This may require assistance with a small clean brush. 


\section{CLEANING}

While it is convenient to use some compressed gas supply as a means of blowing debris from the feeder and sensor, it is recommended that only the vacuum line supplied with the feeder be used.

The catcher jar should also be cleaned after each replicate.

\section{EXAMPLES}

The appendix contains a number of sample runs. The sample splitter was used on a $+420-100$ micron sample. Four replicates were obtained and analyzed uniar varying system settings. Each replicate contained clean glass microspheres with a bulk density less than $1.0 \mathrm{gm} / \mathrm{cc}$. 
APPENDIX A 


\section{REPLICATE ANALYSIS BREAKDOWN}

\begin{tabular}{|c|c|c|c|}
\hline REPLICATE & $\begin{array}{l}\text { POPULATION } \\
\text { MEAN }\end{array}$ & $\begin{array}{l}d(50) \\
\text { MODE } \\
\end{array}$ & REMARKS \\
\hline 1 & 332.1 & 337.5 & 45:1 No suppression \\
\hline 2 & 331.6 & 337.5 & $45: 1$ lst $4 \mathrm{Ch}$. Suppr. \\
\hline 3 & 337.3 & 336.9 & 8:1 No suppression \\
\hline 4 & 353.3 & 346.4 & 8:1 1st $4 \mathrm{Ch}$. Suppr. \\
\hline TOTAL: & 1354.3 & 1358.3 & \\
\hline AVE: & 339. & 340. & \\
\hline
\end{tabular}

* Variation in Replicates

$\begin{array}{lll}\text { Best Case } & 1.7 \% & 0.2 \% \\ \text { Worst Case } & 6.0 \% & 2.7 \%\end{array}$




$$
\begin{aligned}
& 7 \\
& \text { SPR }
\end{aligned}
$$


WIAC PABTICLE BIzE AMALYSIS

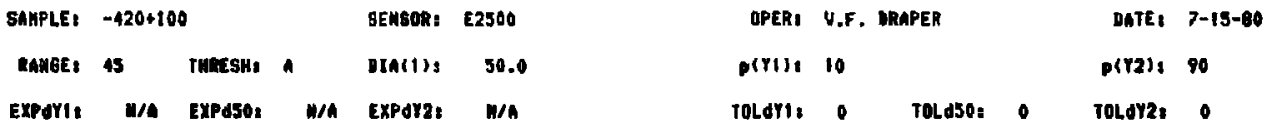

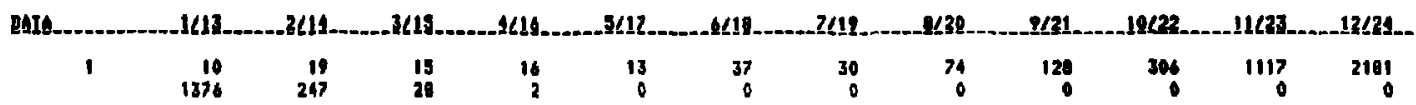

\begin{tabular}{|c|c|c|c|c|c|c|c|c|c|c|c|}
\hline AHALISL & $d s 1 L$. & A48 & ESG & CPE. & zEIE & SI & $\ldots$ & מח & Mie & OLUhE & 12 \\
\hline $\begin{array}{l}1 \\
2 \\
3 \\
4 \\
5 \\
6 \\
7 \\
8 \\
9 \\
10 \\
11 \\
12 \\
13 \\
14\end{array}$ & $\begin{array}{r}54.5 \\
64.3 \\
75.9 \\
89.5 \\
105.5 \\
124.7 \\
147.1 \\
173.6 \\
204.8 \\
241.7 \\
205.2 \\
334.6 \\
397.1 \\
469.6\end{array}$ & $\begin{array}{r}10 \\
19 \\
15 \\
16 \\
13 \\
37 \\
30 \\
74 \\
128 \\
304 \\
1117 \\
2181 \\
1374 \\
247\end{array}$ & 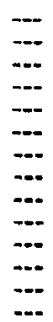 & $\begin{array}{r}10 \\
19 \\
15 \\
16 \\
13 \\
37 \\
30 \\
74 \\
128 \\
106 \\
1117 \\
2101 \\
1376 \\
247\end{array}$ & $\begin{array}{c}0.18 \\
0.34 \\
0.27 \\
0.29 \\
0.23 \\
0.66 \\
0.54 \\
1.32 \\
2.29 \\
5.47 \\
19.95 \\
38.95 \\
24.58 \\
4.41\end{array}$ & 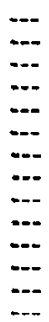 & $\begin{array}{r}0.18 \\
0.52 \\
0.79 \\
1.07 \\
1.30 \\
1.96 \\
2.30 \\
3.62 \\
6.11 \\
11.57 \\
31.52 \\
70.49 \\
95.05 \\
99.46\end{array}$ & $\begin{array}{r}100.00 \\
99.42 \\
99.48 \\
99.21 \\
99.93 \\
98.90 \\
99.04 \\
97.50 \\
96.18 \\
93.09 \\
91.43 \\
68.48 \\
29.42 \\
4.96\end{array}$ & $\begin{array}{l}0.00 \\
0.00 \\
0.00 \\
0.00 \\
0.01 \\
0.03 \\
0.04 \\
0.17 \\
0.47 \\
1.04 \\
11.17 \\
35.04 \\
37.15 \\
10.96\end{array}$ & $\begin{array}{r}0.00 \\
0.00 \\
0.01 \\
0.01 \\
0.02 \\
0.05 \\
0.09 \\
0.26 \\
0.73 \\
2.54 \\
13.77 \\
49.61 \\
04.76 \\
97.72\end{array}$ & $\begin{array}{l}109.00 \\
100.00 \\
109.00 \\
99.99 \\
99.99 \\
97.90 \\
99.95 \\
99.91 \\
99.74 \\
99.27 \\
97.41 \\
96.23 \\
50.39 \\
13.24\end{array}$ \\
\hline
\end{tabular}


gAMPLE: $-420+100$

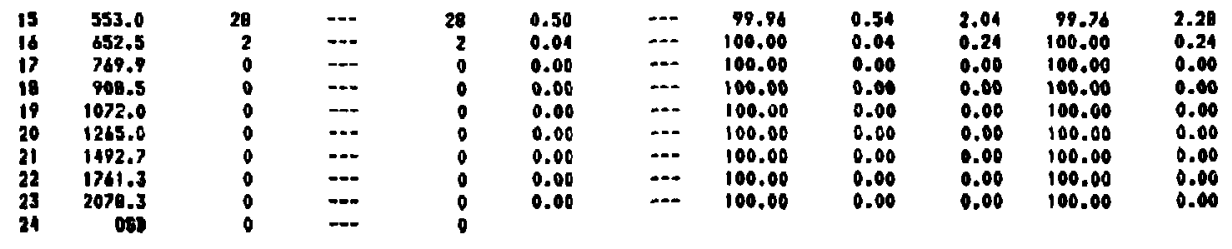

8lHHeRY.-

d(Y) Y1)

d(50)

dstror1!

dIYZLIL.

$\begin{array}{rrrrrrrr}\text { POP } & 332.1 & 258.4 & 537.5 & 113.6 & 1.31 & 1.23 & \\ \text { VOL } & 370.1 & 301.0 & 169.0 & 146.7 & 1.23 & 1.21 & \text { w } \\ \text { FLAB } & & & & & & \end{array}$




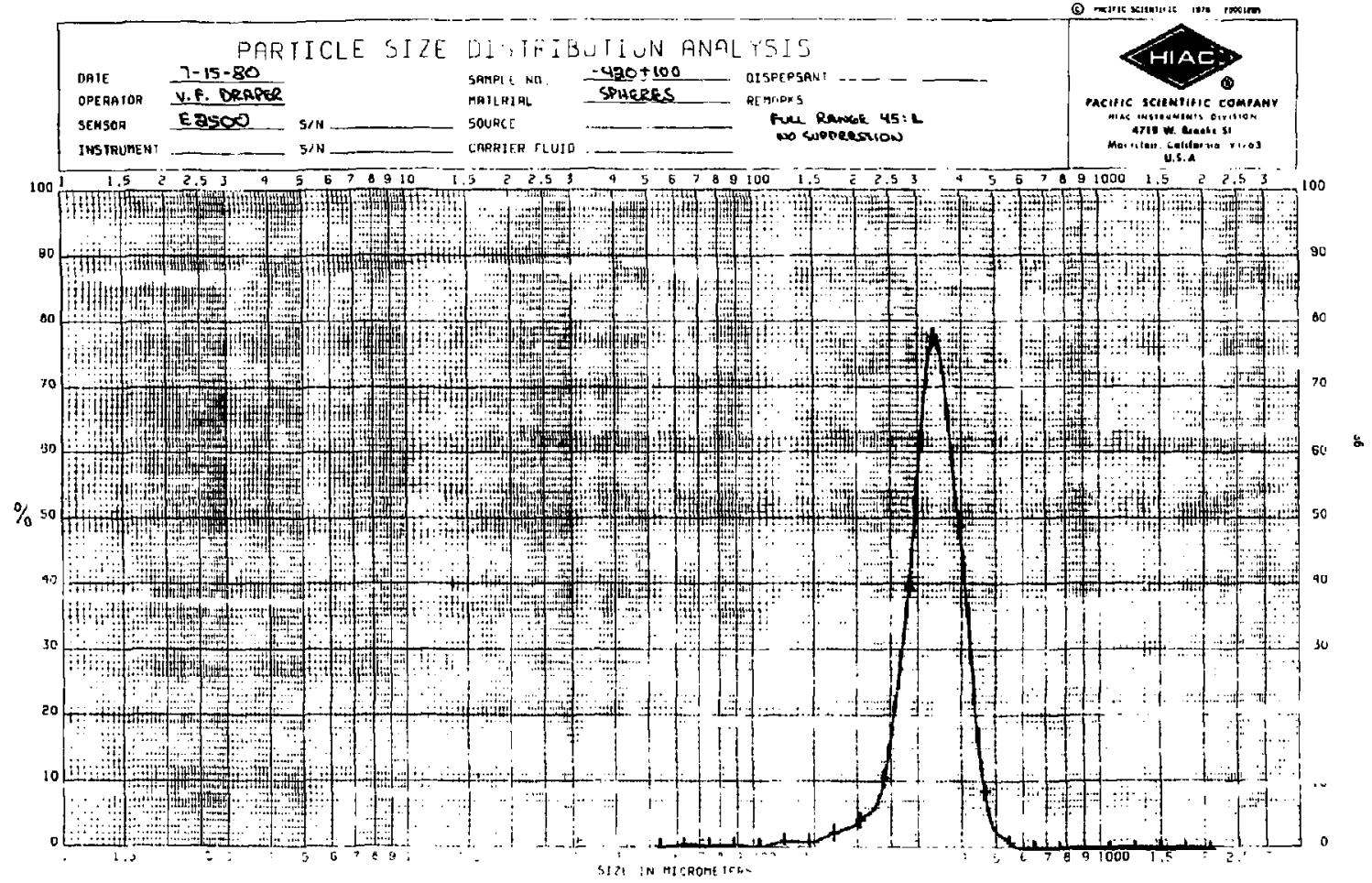




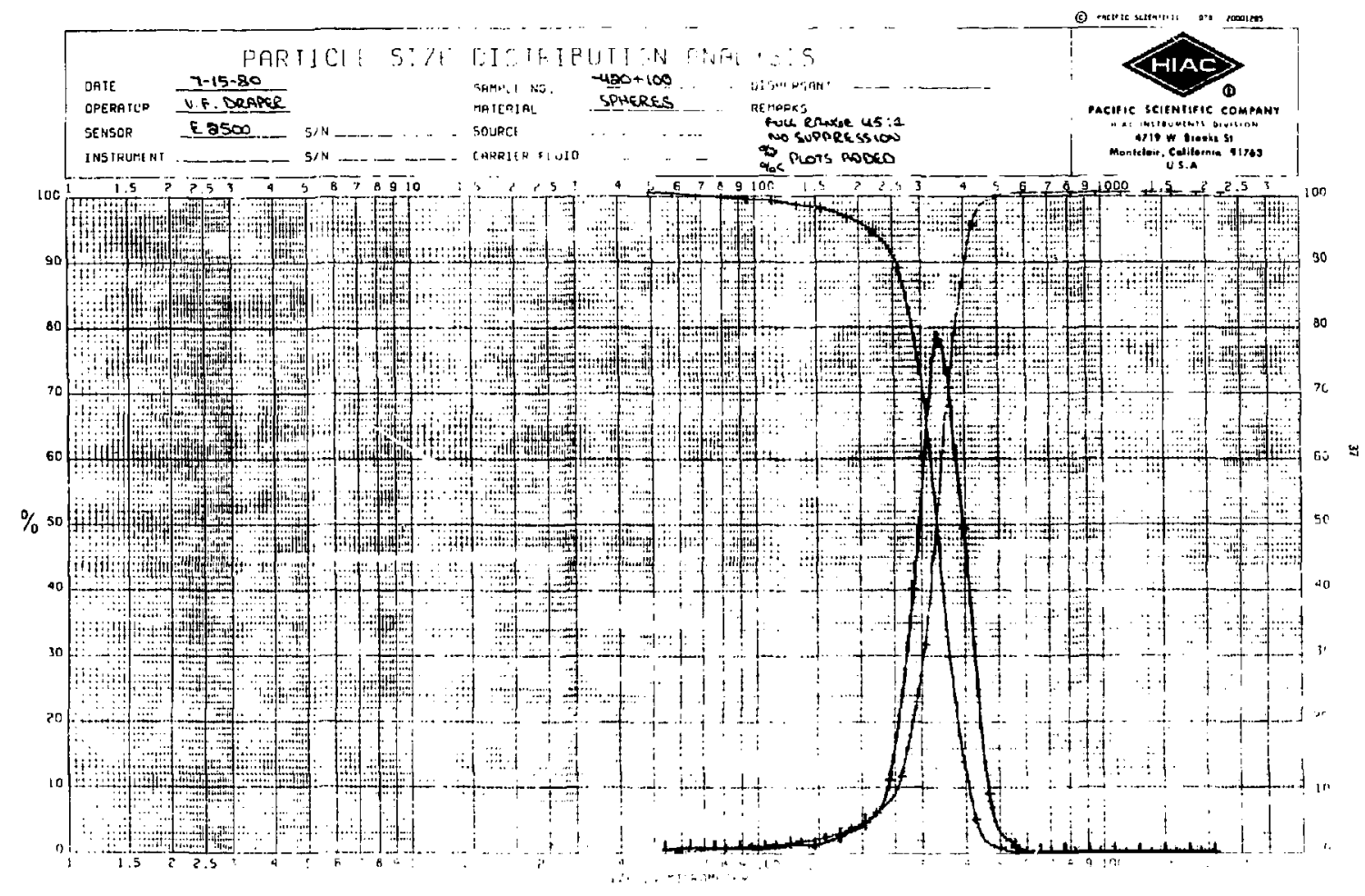


hINC PaAticle sIze amaLrsis

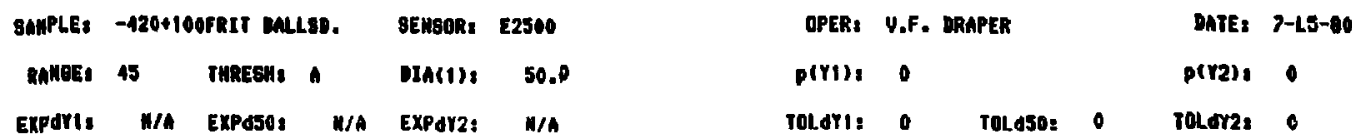

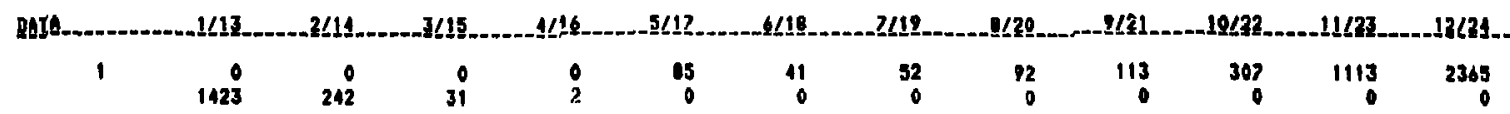

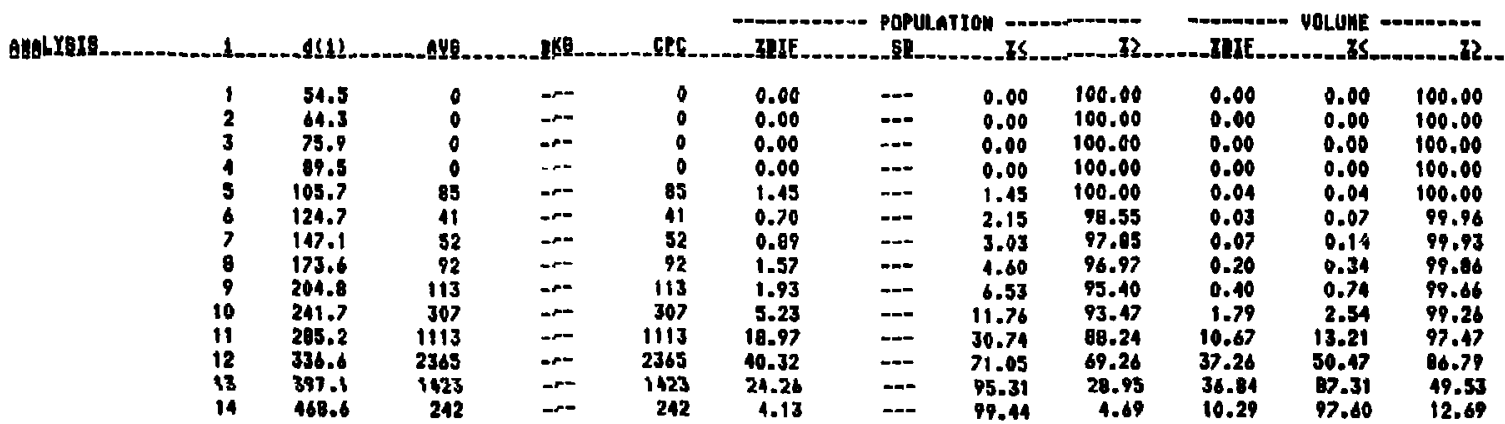


BIIPLE: -420+100FRIT BLLSP.

\begin{tabular}{|c|c|c|c|c|c|c|c|c|c|c|}
\hline $\begin{array}{r}553.0 \\
652.5 \\
769.9 \\
908.5 \\
1072.0 \\
1265.0 \\
1492.7 \\
1761.3 \\
2078.3 \\
080\end{array}$ & $\begin{array}{r}31 \\
2 \\
0 \\
0 \\
0 \\
0 \\
0 \\
0 \\
0 \\
0\end{array}$ & $\begin{array}{l}-- \\
-- \\
-- \\
-- \\
-- \\
-- \\
-- \\
--\end{array}$ & $\begin{array}{r}31 \\
2 \\
0 \\
0 \\
0 \\
0 \\
0 \\
0 \\
0 \\
0\end{array}$ & $\begin{array}{l}0.53 \\
0.03 \\
0.00 \\
0.00 \\
0.00 \\
0.00 \\
0.00 \\
0.00 \\
0.00\end{array}$ & $\begin{array}{l}--- \\
--- \\
--- \\
-- \\
-- \\
--- \\
--- \\
---\end{array}$ & $\begin{array}{r}99.97 \\
100.00 \\
100.00 \\
100.00 \\
100.00 \\
100.00 \\
100.00 \\
100.00 \\
100.00\end{array}$ & $\begin{array}{l}0.56 \\
0.03 \\
0.00 \\
0.00 \\
0.00 \\
0.00 \\
0.00 \\
0.00 \\
0.00\end{array}$ & $\begin{array}{l}2.17 \\
0.23 \\
0.00 \\
0.00 \\
0.00 \\
0.00 \\
0.00 \\
0.00 \\
0.00\end{array}$ & $\begin{array}{r}99.77 \\
100.00 \\
100.00 \\
100.00 \\
100.00 \\
100.00 \\
100.00 \\
100.00 \\
100.00\end{array}$ & $\begin{array}{l}2.40 \\
0.23 \\
0.00 \\
0.00 \\
0.00 \\
0.00 \\
0.00 \\
0.00 \\
0.00\end{array}$ \\
\hline
\end{tabular}

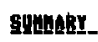

POP 331.6

vOL 369.6

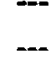

337.5

FLAO

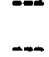

364.4 


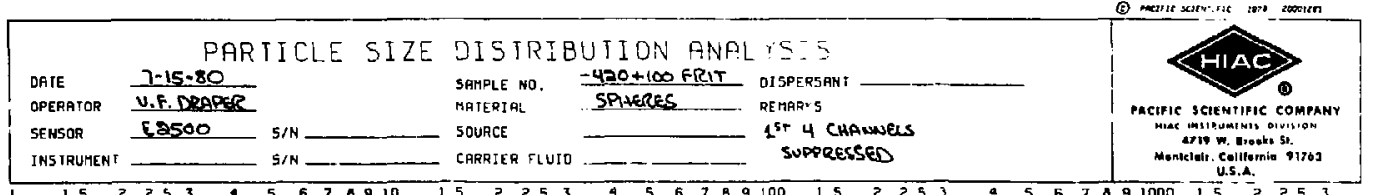

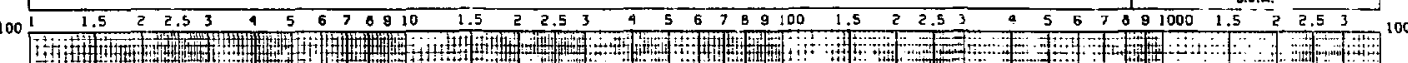
-11+0

$90 \frac{1}{4}$

20 (a)

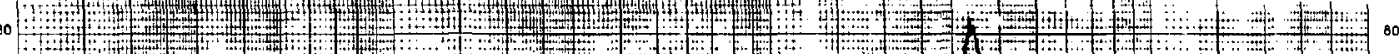

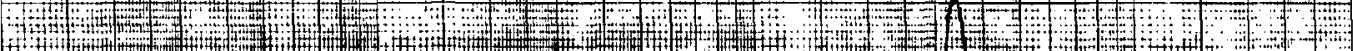

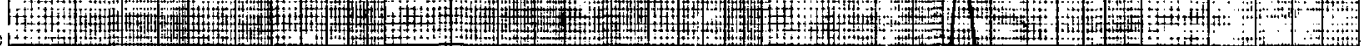
70 19 (150)

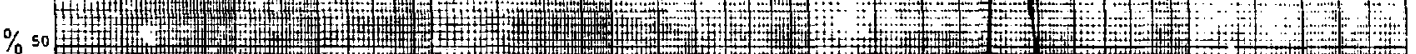
(1) ${ }_{40} \mathrm{C}$ -

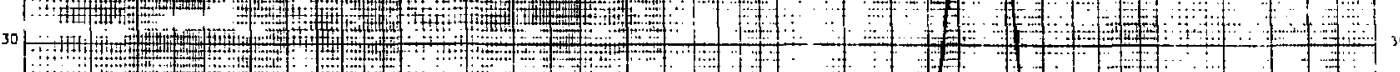
(a) 10 ond

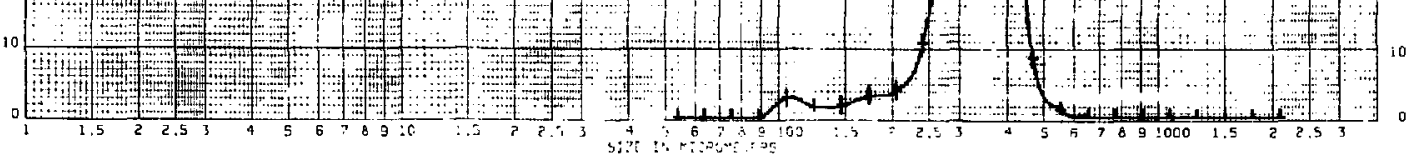


hIAC PaRticle stze amalrsis

\begin{tabular}{|c|c|c|c|c|c|c|c|c|c|c|c|}
\hline GAHPLE: & $-420+10$ & OEXP SCALE & & SENGOR & E2500 & BPERE & Y.F. & BRAPER & & BATE! & $7-L 5-80$ \\
\hline AMUBE: & B & THAESAI & 5 & Dratis: & 200.0 & $p(Y 1):$ & 0 & & & piyz): & 0 \\
\hline Expdy1: & $n / A$ & EXPABOI & $n / h$ & EXPdY2: & h/h & TOLdTI: & 0 & TOLO5O: & 0 & TOLdY2: & 0 \\
\hline
\end{tabular}

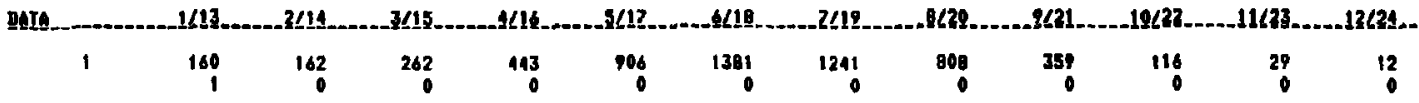

\begin{tabular}{|c|c|c|c|c|c|c|c|c|c|c|c|}
\hline $\begin{array}{c}1 \\
2 \\
3 \\
4 \\
5 \\
6 \\
7 \\
6 \\
9 \\
10 \\
11 \\
12 \\
13 \\
14\end{array}$ & $\begin{array}{l}209.5 \\
229.3 \\
231.0 \\
274.7 \\
300.7 \\
329.2 \\
360.3 \\
394.4 \\
431.7 \\
972.6 \\
517.3 \\
564.2 \\
218.8 \\
678.5\end{array}$ & $\begin{array}{r}160 \\
162 \\
262 \\
143 \\
106 \\
1381 \\
1241 \\
608 \\
354 \\
116 \\
29 \\
12 \\
1 \\
0\end{array}$ & 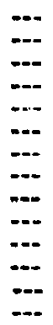 & $\begin{array}{r}166 \\
162 \\
262 \\
143 \\
906 \\
1301 \\
1241 \\
609 \\
759 \\
116 \\
29 \\
12 \\
1 \\
0\end{array}$ & $\begin{array}{c}2.72 \\
2.76 \\
4.46 \\
7.53 \\
15.41 \\
23.49 \\
21.11 \\
13.74 \\
6.11 \\
1.97 \\
0.49 \\
0.20 \\
0.02 \\
0.00\end{array}$ & 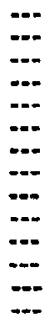 & $\begin{array}{r}2.72 \\
5.49 \\
9.93 \\
17.47 \\
32.87 \\
56.36 \\
77.47 \\
91.21 \\
97.31 \\
99.29 \\
99.78 \\
99.78 \\
100.00 \\
100.00\end{array}$ & $\begin{array}{r}100.00 \\
97.20 \\
94.52 \\
90.07 \\
82.53 \\
67.13 \\
43.64 \\
22.53 \\
0.79 \\
2.69 \\
0.71 \\
0.22 \\
0.02 \\
0.00\end{array}$ & $\begin{array}{r}0.60 \\
0.79 \\
1.68 \\
3.74 \\
10.02 \\
20.04 \\
23.61 \\
20.17 \\
11.75 \\
4.98 \\
1.63 \\
0.89 \\
0.10 \\
0.00\end{array}$ & $\begin{array}{c}0.40 \\
1.39 \\
3.08 \\
6.81 \\
16.84 \\
36.87 \\
60.49 \\
90.45 \\
92.40 \\
97.36 \\
99.02 \\
99.90 \\
100.00 \\
100.00\end{array}$ & $\begin{array}{r}100.00 \\
99.40 \\
90.61 \\
96.92 \\
93.19 \\
93.16 \\
63.13 \\
39.51 \\
19.35 \\
7.60 \\
2.62 \\
0.17 \\
0.10 \\
0.00\end{array}$ \\
\hline
\end{tabular}


SAMPL: - 420+100EXP SCALE

\begin{tabular}{|c|c|c|c|c|c|c|c|c|c|c|}
\hline $\begin{array}{rr}15 & 742.7 \\
16 & 912.9 \\
17 & 899.9 \\
18 & 974.1 \\
19 & 1046.2 \\
26 & 1187.1 \\
21 & 1277.5 \\
22 & 1398.4 \\
22 & 1530.7 \\
24 & 0 S 0\end{array}$ & $\begin{array}{l}0 \\
0 \\
0 \\
0 \\
0 \\
0 \\
0 \\
0 \\
0\end{array}$ & $\begin{array}{l}\ldots \\
\ldots \\
\ldots \\
\ldots \\
\ldots \\
\ldots \\
\ldots\end{array}$ & $\begin{array}{l}0 \\
0 \\
0 \\
0 \\
0 \\
0 \\
0 \\
0 \\
0\end{array}$ & $\begin{array}{l}0.00 \\
0.00 \\
0.00 \\
0.00 \\
0.00 \\
0.00 \\
0.00 \\
0.00 \\
0.00\end{array}$ & 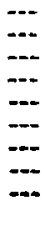 & $\begin{array}{l}100.00 \\
100.00 \\
100.00 \\
100.00 \\
100.00 \\
100.00 \\
100.00 \\
100.00 \\
100.00\end{array}$ & $\begin{array}{l}0.00 \\
0.00 \\
0.00 \\
0.00 \\
0.00 \\
0.00 \\
0.00 \\
0.00 \\
0.00\end{array}$ & $\begin{array}{l}0.00 \\
0.00 \\
0.00 \\
0.00 \\
0.00 \\
0.00 \\
0.00 \\
0.00 \\
0.00\end{array}$ & $\begin{array}{l}100.00 \\
109.00 \\
100.00 \\
100.00 \\
100.00 \\
100.00 \\
100.00 \\
100.00 \\
100.00\end{array}$ & $\begin{array}{l}0.00 \\
0.00 \\
0.00 \\
0.00 \\
0.00 \\
0.00 \\
0.00 \\
0.00 \\
0.00\end{array}$ \\
\hline
\end{tabular}

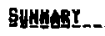
스토스느는.

d(YI) 24

d59)

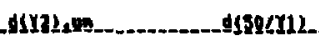

A1ya:son

\begin{tabular}{|c|c|c|c|c|c|c|}
\hline$P O P$ & 337.3 & - & 336.9 & $\ldots$ & -.. & -- \\
\hline VOL & 346.6 & - & 363.7 & $=$ & -.. & -.. \\
\hline
\end{tabular}




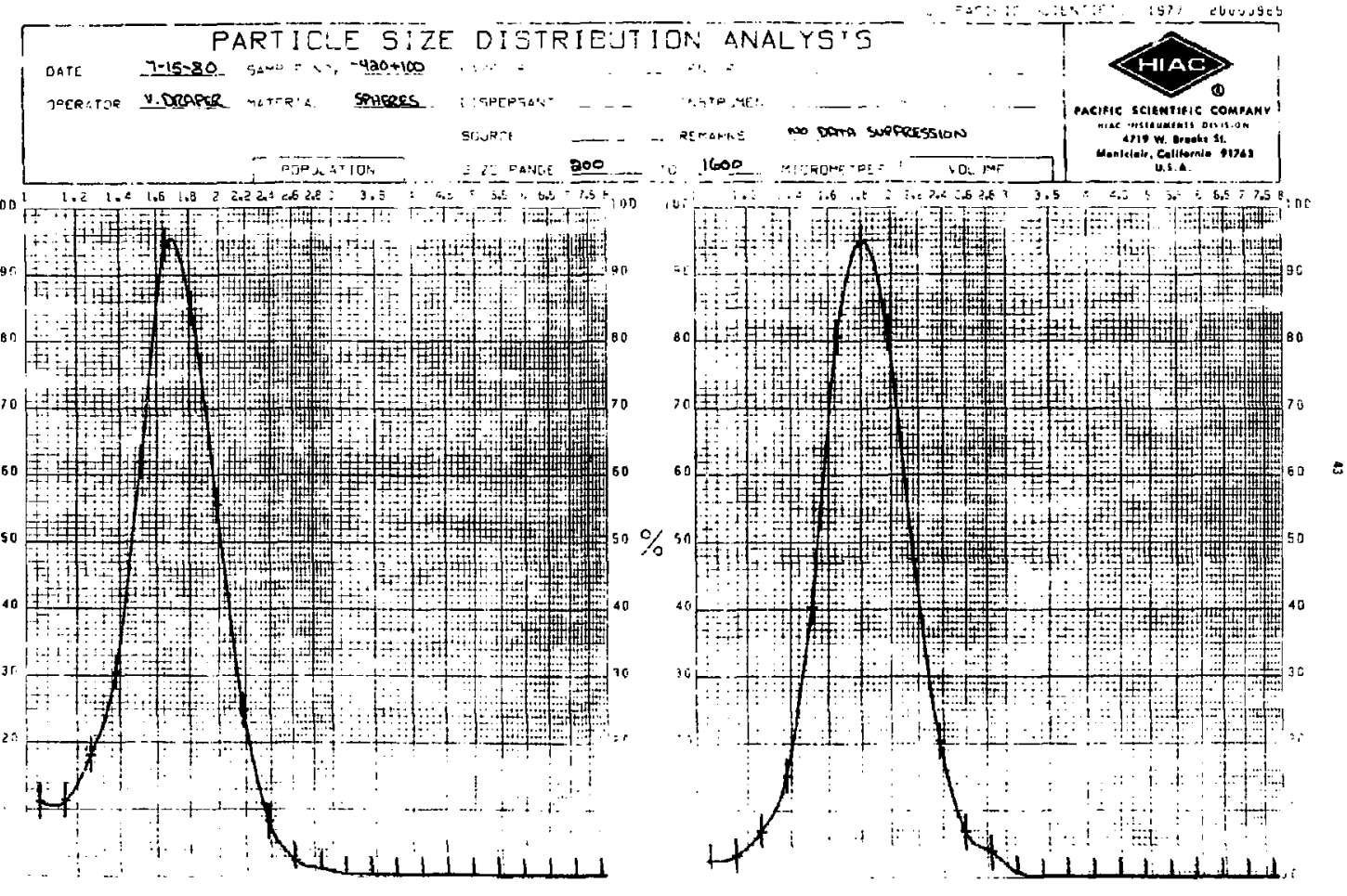


hIac particle size ahalysis

\begin{tabular}{|c|c|c|c|c|c|c|c|c|c|c|}
\hline SAMPLEI & $-420+100$ & FRIT DA & Th 5 & SENSOR: & {$[2500$} & DPER: & U.F. DRAPER & & DATE: & $7-L 5-80$ \\
\hline RANEE: & 8 & THRESH : & $\mathbf{B}$ & DIAI1): & 200.0 & p〈YI & 0 & & $p(Y 2):$ & 0 \\
\hline EXPdY : & $M / A$ & EXPd50: & H/A & EXPdY2: & $H / h$ & TOLdY: & TOLd5O: & $\mathbf{0}$ & TOLAY2: & 0 \\
\hline
\end{tabular}

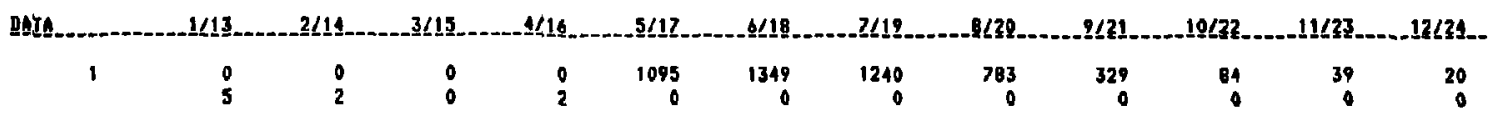

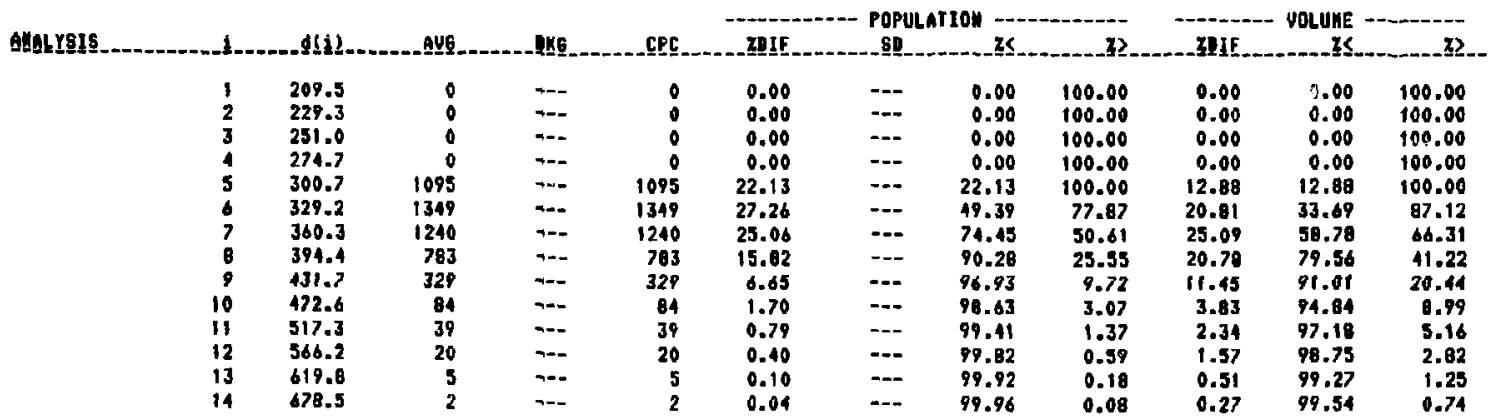


SAMPLE, $-420+100$ FRIT EATA S

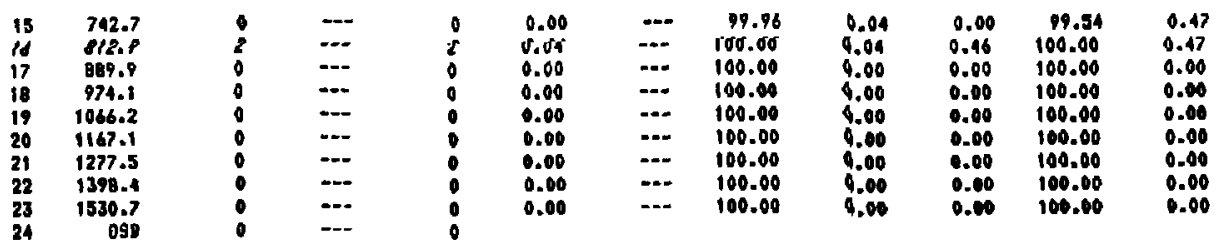

gunumisy HEN d(Mt) Alsol_us

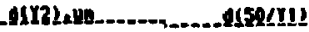
ALRLSL.

$\begin{array}{ll}\text { POP } & 353.3 \\ \text { vol } & 376.9\end{array}$

346.4

366.3
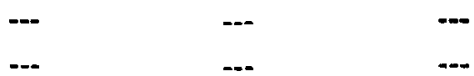

FLAB 


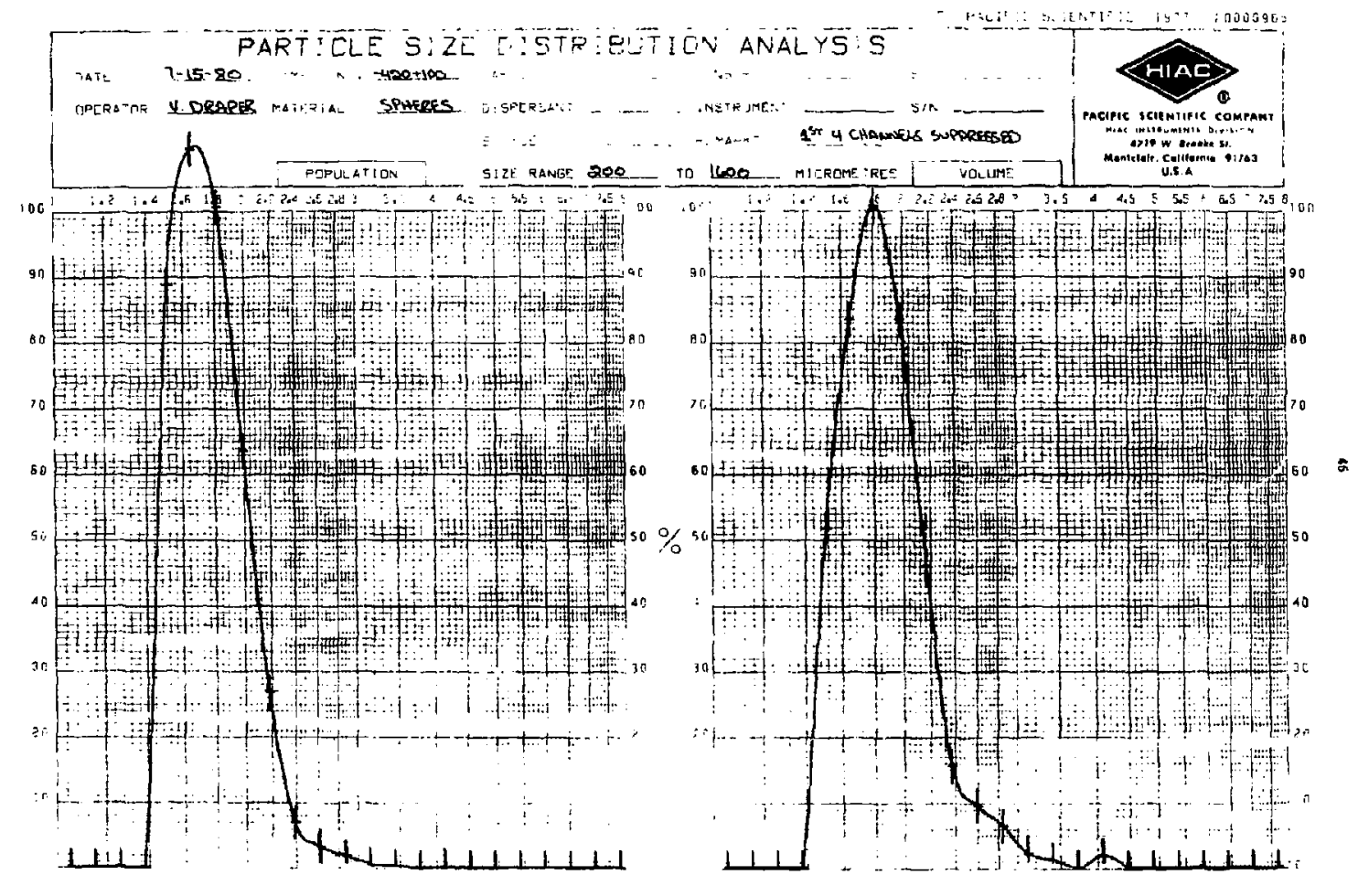


47

APPENDIX B

CAL IBRAT ION DATA SHEET 
LAWERENCE LIVERMORE WO 4140 E-2500 S/N 06B

BD. \#6 S/N 2044

\author{
FAllGE: $>15$ \\ DIA(1): $>50.0$ \\ SLOPE: 22.000 \\ IHIRCPJ: $>0.001$ \\ HOISE: >6.6
}

$\begin{array}{rrr}\text { CH } & \text { IIAHETER } & \text { VOL TAGE (NV) } \\ 1 & 50.0 & 9.10 \\ 2 & 59.0 & 10.08 \\ 3 & 69.6 & 11.45 \\ 1 & 82.1 & 13.35 \\ 5 & 96.9 & 16.00 \\ 6 & 114.4 & 19.68 \\ 7 & 135.0 & 24.82 \\ 8 & 159.3 & 31.97 \\ 9 & 187.9 & 11.92 \\ 10 & 221.8 & 55.78 \\ 11 & 261.7 & 75.07 \\ 12 & 308.8 & 101.94 \\ 13 & 364.3 & 139.35 \\ 14 & 429.9 & 191.43 \\ 15 & 507.3 & 263.96 \\ 16 & 598.6 & 364.94 \\ 17 & 706.4 & 505.54 \\ 18 & 833.5 & 701.31 \\ 19 & 983.5 & 973.90 \\ 20 & 1160.5 & 1353.44 \\ 21 & 1369.4 & 1881.89 \\ 22 & 1615.9 & 2617.71 \\ 23 & 1906.7 & 3642.23 \\ 21 & 2249.9 & 5068.25\end{array}$

\author{
RAHFE: $>8$ \\ D]A(1): 2200.0 \\ SLOPE: $>2.000$ \\ IHIRCPT: $>0.001$ \\ HOISE: $>6.6$
}

